\title{
Birt-Hogg-Dube Sendromu
}

\section{Birt-Hogg-Dube Syndrome}

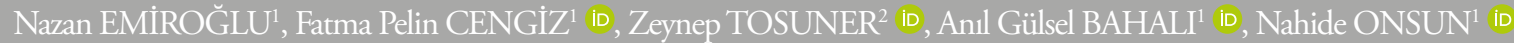

${ }^{1}$ Bezmialem Vakıf Üniversitesi Tıp Fakültesi, Deri ve Zührevi Hastalıklar Anabilim Dalı, İstanbul, Türkiye

${ }^{2}$ Bezmialem Vakıf Üniversitesi Tıp Fakültesi, Patoloji Anabilim Dalı, İstanbul, Türkiye

\section{öz}

Birt-Hogg-Dube sendromu fibrofolikülomalar, anjiyofibromlar, fibroepitelyal polipler ve trikodiskomalar da dahil olmak üzere birçok karakteristik deri bulgusu içeren bir sendromdur. Otozomal dominant geçişlidir. Aynı zamanda akciğer kistleri, spontan pnömotoraks ve böbrek tümörleri gibi ekstrakutanöz bulgular da içerir. Sistemik tutulum nedeniyle erken tanı ve tedavisi önemlidir. Burada Birt-Hogg-Dube sendromu tanısı alan 53 yaşındaki bir erkek hasta sunuldu.

Anahtar Kelimeler: Trikodiskoma, Birt-Hogg-Dube sendromu, fibrofoliküloma

\section{ABSTRACT}

Birt-Hogg-Dube syndrome is characterized by cutaneous findings, including fibrofolliculomas, angiofibromas, fibroepithelial polyps, and trichodiscomas. It is an inherited autosomal dominant disorder. This syndrome also includes extra-cutaneous findings, such as pulmonary cysts, spontaneous pneumothorax, and renal cancer. Because of the systemic involvement, early diagnosis and treatment are important. Here, we report the case of a 53-year-old man diagnosed as having Birt-Hogg-Dube syndrome.

Keywords: Trichodiscoma, Birt-Hogg-Dube syndrome, fibrofolliculoma

\section{Giriş}

Birt-Hogg-Dube sendromu (BHDS) klinik olarak fibrofoliküloma, trikodiskoma, akciğer kistleri, spontan pnömotoraks ve böbrek tümörleri ile klinik karakterize otozomal dominant bir sendromdur. Bu sendroma follikülin (FLCN) genindeki mutasyonlar neden olur. Burada Birt-Hogg-Dubé sendromlu 53 yaşında erkek bir olguyu sunuyoruz.

\section{Olgu Sunumu}

Elli üç yaşında erkek hasta polikliniğimize yüzde ve boyunda yağ bezesi şikayeti ile başvurdu. Hastanın özgeçmişinden bilinen vertigosu, servikal spondilozu ve hipertansiyonu olduğu öğrenildi. Soygeçmişinde ise annede böbrek hastalığı (tam olarak tanııın bilmiyor), babada ise akciğer kanserinden ölüm öyküsü vardı. Erkek kardeşinde de benzer lezyonların mevcut olduğunu ifade ediyordu. Dermatolojik muayenesinde boyunda çok sayıda, yanaklarda ve alında daha az sayıda olmak üzere yaygın beyazımsı, kubbe şeklinde birkaç milimetre çaplarında papüller görüldü (Resim 1a-c). Hastanın yapılan sistemik muayenesi, hemogram ,biyokimya, tam idrar ve gaita tetkikleri doğaldı. Hastanın deri lezyonlarından biyopsi alındı ve histopatolojik olarak trikodiskoma ile uyumlu idi (Resim 2, 3). Hastanın deri biyopsisi sonucunun trikodiskoma ile uyumlu olması nedeni ile Birt-Hogg-Dubé sendromu düşünülerek ileri araştırma yapılmasına karar verildi. Hastanın sistemik tutulum açısından yapılan tetkiklerinde, torako-abdomino-pelvik tomografisinde bening renal kistler dışında bulguya rastlanmadı. Hasta takibe alındı ve benzer şikayetleri olan kardeşi de tanı ve tarama amaçlı kliniğimize çağıııldı.

\section{Tartışma}

1977 yllında ilk olarak Birt ve ark. (1) tarafından tanımlanan Birt-Hogg-Dubé sendromu(BHDS) otozomal dominant kalıtım gösterir. Bu sendroma 17. kromozomun p11.2 bölgesinin 14. ekzonunda yer alan follikülin (FLCN) geninde meydana gelen çoklu mutasyonların neden olduğu saptanmıştır. Follikülin proteininin tümör supresor fonksiyonunu olduğu tahmin edilmektedir ancak henüz doğrulanmamıştır. Klinik olarak görülen tümörler bunu destekler niteliktedir. Sendromun tanısının çoğu zaman konulamadığı tahmin edilmekte olup bu nedenle insidansı belirlenememiştir. Dünyada FLCN mutasyonları içeren yaklaşık 200 aile bildirilmiştir $(2,3)$.

Cite this article as: Emiroğlu N, Cengiz FP, Tosuner Z, Bahalı AG, Onsun N. Birt-Hogg-Dube Syndrome. Bezmialem Science 2018; 6(3): 220-2.

Yazışma Adresi/Address for Correspondence: Nazan EMiROČLU, Bezmialem Vakıf Üniversitesi Tıp Fakültesi, Deri ve Zührevi Hastalıklar Anabilim Dalı, İstanbul, Türkiye E-mail: dr.nazanyilmaz@hotmail.com

OTelif Hakkı 2018 Bezmialem Vakıf Üniversitesi - Makale metnine www.bezmialemscience.org web sayfasından ulaşslabilir.

OCopyright 2018 by Bezmialem Vakif University - Available online at www.bezmialemscience.org
Geliş Tarihi / Received : 11.10 .2016 Kabul Tarihi / Accepted: 20.03.2017 

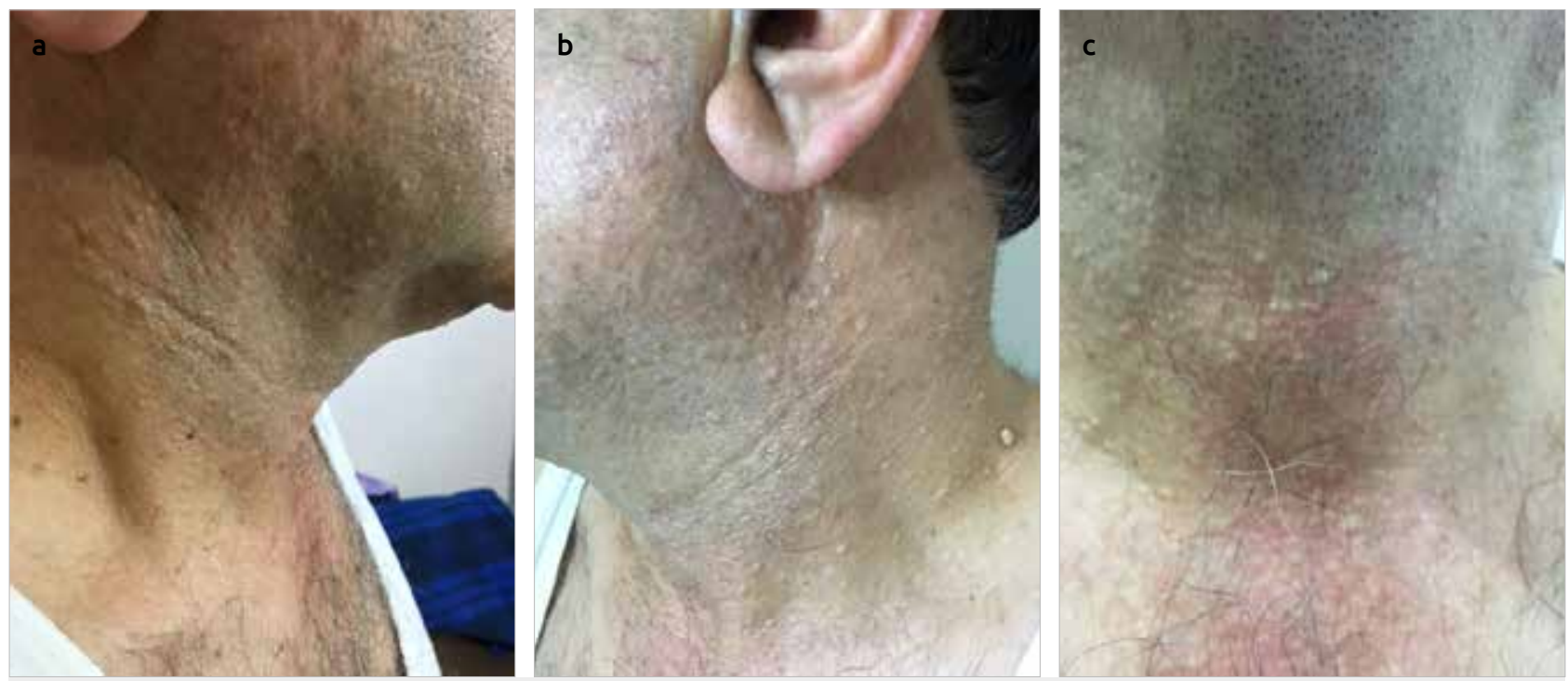

Resim 1. a-c. Boyunda çok sayıda yaygın beyazımsı, kubbe şeklinde birkaç milimetre çaplarında papüller

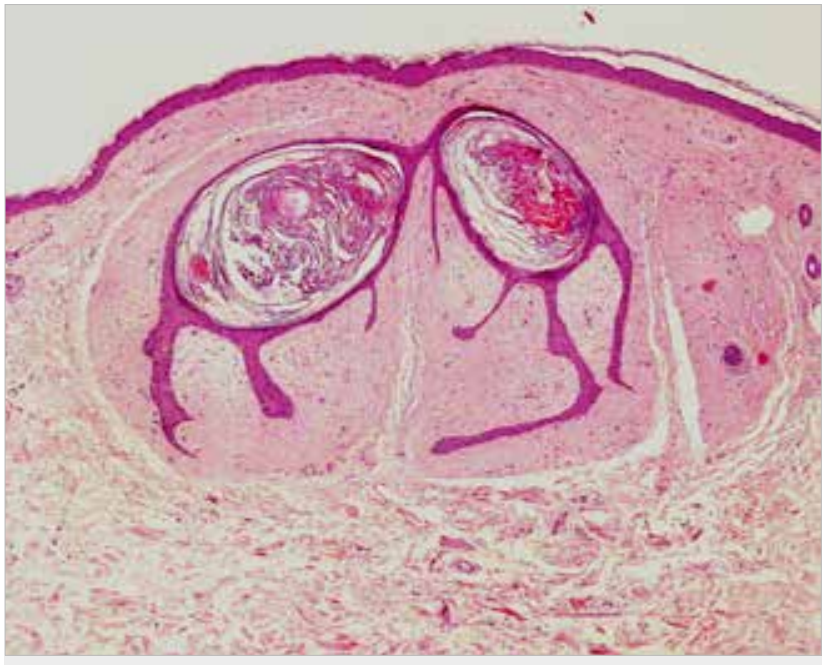

Resim 2. Histopatolojik incelemede atrofik epidermis altında, iki taraftan ince uzun foliküler epitel tarafından çevrelenmiş kubbe şeklinde bir kistik lezyon. Kist serbest kıl şaftları ve lameller keratin içeriyor. Hematoksilen Eosin $\times 40$

Birt-Hogg-Dube sendromu genellikle hayatın üçüncü dekadında başlayan yüz ve gövde üst kısmında ortaya çıkan deri renginde, asemptomatik, solid, yumuşak, 2-4mm, kubbe şeklinde papüller ile karakterizedir. Kulak tutulumu BHDS için oldukça spesifiktir. BHDS'de deri tutulumunun klasik triadı fibrofolikülomalar, trikodiskoma ve akrokordonları içerir. Bunların dişında her zaman olmamakla beraber anjiyofibromlar, lipomlar, anjiyolipomlar, oral polipler ve kollojenoma gibi deri tümörleri de görülebilmektedir (4). BHDS’nin diğer sık görülen deri dışı klinik bulguları akciğer kistleri, spontan pnömotoraks ve böbrek tümörleridir (4).

Deri ve sistemik tutulumun çeşitliliği nedeniyle Avrupa BirtHogg-Dubé Konsorsiyumu (European Birt- Hogg-Dube Consortium) tarafından hastalığın tanısı için bazı kriterler

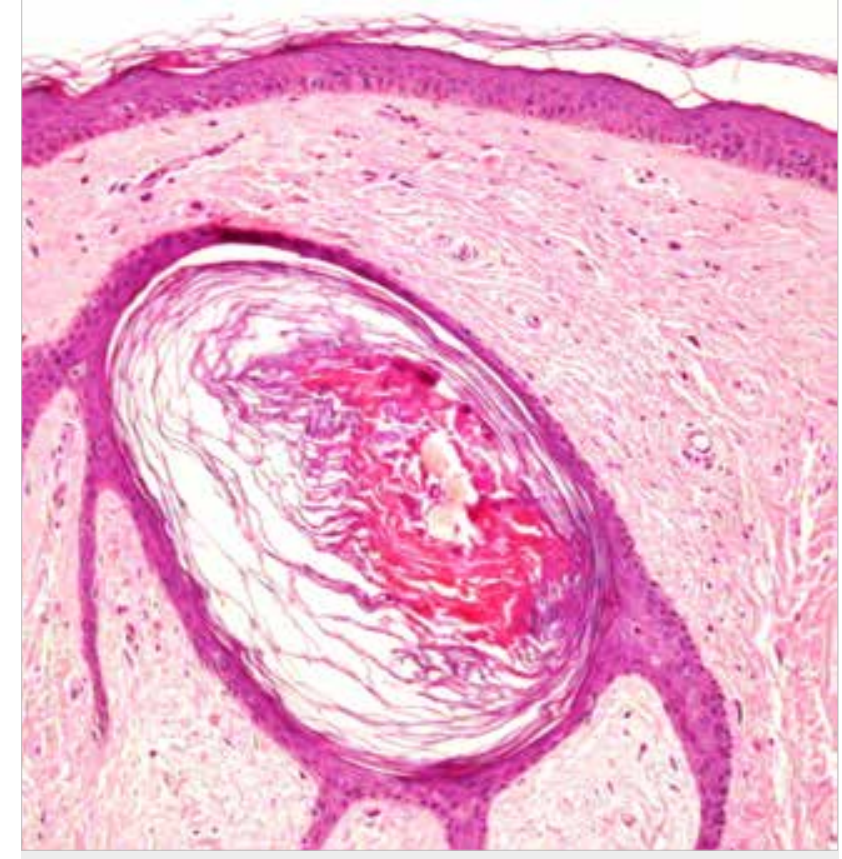

Resim 3. Düzensiz demetler şeklinde düzenlenen artmış fibriler kollajen, sayıca artmış yıldız şeklindeki fibroblastlar ve müsinöz stroma. Hematoksilen Eosin x100

önerilmiştir. Birt-Hogg-Dubé sendromu tanısı konulabilmesi için hastaların aşağıdaki kriterlerden 1 majör veya 2 minör kriteri karşılaması gerekir. Bunlar: Majör kriterler 1) Yetişkinlikte oluşan en az bir tanesi histopatoloik tanı almış sayısı $\geq 5$ fibrofoliküloma veya trikodiskoma 2) FLCN geninde mutasyon. Minör Kriterler: 1) Çok sayıda akciğer kistleri (bilateral ve bazal yerleşimli \pm spontan pnömotoraks) 2) Böbrek kanseri (50 yaş öncesi veya multifokal, bilateral veya miks kromofob, onkositik histopatoloji) 3) Birinci derece akrabalarda Birt-Hogg-Dubé sendromu (5). Sonuç olarak yetişkinlikte oluşan en az bir tanesi histopatolojik tanı almış, en az 5 adet trikodiskoma sistemik hiçbir bulgu eşlik etmeksi- 
zin Birt-Hogg-Dubé sendromu tanısı koydurmaktadır. Bizim hastamızda da histopatolojik olarak da doğrulan multipl trikodiskomalar mevcuttu.Aile öyküsü olmakla birlikte kardeşi muayeneye çağırıldı ancak gelmedi. Bening renal ksitler dışında sistemik bulgu izlenmeyen hasta uzun süreli takibe alındı.

Birt-Hogg-Dube sendromlu hastalarda sağlıklı popülasyona göre böbrek tümörü riski 16 kat, spontan pnömotoraks riski ise 50 kat artmıştır. Pnömotoraks muhtemelen akciğer kistleri ile ilişkilidir (6). İleri yaş ve erkek cinsiyette böbrek tümörü riski artarken, spontan pnömotoraks riski yaş ile azalmaktadır (7). Bu nedenle takipteki hastalarda renal tümörün erken tanısı açısından yapılacak olan rutin görüntüleme tetkiklerine 40 yaşından itibaren başlanabilir (7).

Birt-Hogg-Dube sendromlu hastalarda daha az sıklıkla intestinal polipler, tiroid nodülü, tiroid kistleri, parotid onkositom, paratiroid adenom, koroidal melanom, koryoretinopati de görülebilir (8).

Hastaların yaklaşık \%80'ninde izlenen karakteristik deri lezyonları olan trikodiskoma ve fibrofoliküloma genellikle 35 yaşından sonra ortaya çıkar ve sendromun en önemli ipucudur (9). Asemptomatik seyirli, deri renginde kubbe şeklinde olan, baş boyun ve gövdenin üst kısmını sıklıkla tutan bu lezyonlar başka birçok tümörle karışabilmektedir. Mikst ektodermal ve mezodermal orjinli bu tümörlerin ayırıcı tanısında multipl fasyal papüllerin görüldüğü diğer kalıtsal hastalıklar ön plandadır. Bu epitelyal lezyonlar trikilemmomaların görüldüğü Cowden sendromu, trikoepitelyomaların görüldüğü Brooke-Spiegler sendromu ve Rombo sendromu, bazaloid foliküler hamartomların görüldügü bazaloid foliküler hamartom sendromu ve anjiofibromların görüldüğü tüberoskleroz$\operatorname{dur}(9,10)$.

\section{Sonuç}

Olgumuzun nadir görülen bir sendrom olması açısından bildirimi önemli olup, bu tür sendromlarda deri bulgularının tanınmasının sistemik tutulumun takibi ve özellikle malignitelerde erken tanıyı kolaylaştırma açısından önemlidir.

Hasta Onamı: Yazılı hasta onamı bu çalışmaya katılan hastadan alınmıştır.

Hakem Değerlendirmesi: Dış bağımsız.

Yazar Katkıları: Tasarım - N.E.; Kaynaklar - F.P.C.; Malzemeler N.O.; Veri Toplanması ve/veya İşlemesi - Z.T.; Analiz ve/veya Yorum - A.G.B.; Literatür Taraması - N.E.; Yazıyı Yazan - N.E.; Eleştirel İnceleme - N.O.

Çıkar Çatışması: Yazarlar çıkar çatışması bildirmemişlerdir.
Finansal Destek: Yazarlar bu çalışma için finansal destek almadıklarını beyan etmişlerdir.

Informed Consent: Written informed consent was obtained from patient who participated in this study.

Peer-review: Externally peer-reviewed.

Author Contributions: Design - N.E.; Resources - F.P.C.; Materials - N.O.; Data Collection and/or Processing - Z.T.; Analysis and/ or Interpretation - A.G.B.; Literature Search - N.E.; Writing Manuscript - N.E.; Critical Review - N.O.

Conflict of Interest: The authors have no conflicts of interest to declare.

Financial Disclosure: The authors declared that this study has received no financial support.

\section{Kaynaklar}

1. Birt AR, Hogg GR, Dubé WJ. Hereditary multiple fibrofolliculomas with trichodiscomas and acrochordons. Arch Dermatol 1977; 113: 1674-7. [CrossRef]

2. Dal Sasso AA, Belém LC, Zanetti G, Souza CA, Escuissato DL, Irion KL, et al. Birt-Hogg-Dubé syndrome. State-of-the-art review with emphasis on pulmonary involvement. Respir Med 2015; 109: 289-96. [CrossRef]

3. Shin WW, Baek YS, Oh TS, Heo YS, Son SB, Oh CH, et al. Birt-hogg-dubé syndrome, a rare case in Korea confirmed by genetic analysis. Ann Dermatol 2011; 23(Suppl 2): S193-6. [CrossRef]

4. Truchuelo MT, Alcántara J, Allende I, Almazán-Fernández FM, Boixeda P, González C. Multiple Facial Papules of Birt-HoggDubé Syndrome Treated with a CO(2) Laser. Ann Dermatol 2011; 23(Suppl 2): S279-80. [CrossRef]

5. Menko FH, van Steensel MA, Giraud S, Friis-Hansen L, Richard S, Ungari S, et al. Birt-Hogg-Dubé syndrome: diagnosis and management. Lancet Oncol 2009; 10: 1199-206. [CrossRef]

6. Pritchett EN, Kim J, Patel K, Patel T, Cusack CA. Birt-HoggDubé syndrome in an African patient and a novel mutation in the FLCN gene. JAMA Dermatol 2015; 151: 348-9. [CrossRef]

7. Kim EH, Jeong SY, Kim HJ, Kim YC. A case of BirtHogg-Dubé syndrome. J Korean Med Sci 2008; 23: 332-5. [CrossRef]

8. Akay BN, Parlak N, Akyol A, Heper AO. A Case with Birt Hogg Dubé Syndrome. Turk J Dermatol 2013; 7: 245-7. [CrossRef]

9. Vincent A, Farley M, Chan E, James WD. Birt-Hogg-Dube syndrome: a review of the literature and the differential diagnosis of firm facial papules. J Am Acad Dermatol 2003; 49: 698-705. [CrossRef]

10. Vernooij M, Claessens T, Luijten M, van Steensel MA, Coull BJ. Birt-Hogg-Dubé syndrome and the skin. Fam Cancer 2013; 12: 381-5. [CrossRef] 